\title{
Moral distress - a threat to dementia care? A qualitative study of nursing staff members' experiences in long-term care facilities
}

\author{
May Helen Midtbust ${ }^{1 *}$, Eva Gjengedal ${ }^{2}$ and Rigmor Einang Alnes ${ }^{1}$
}

\begin{abstract}
Background: Dementia is a public health priority worldwide due to its rapidly increasing prevalence and poses challenges with regard to providing proper care, including end-of-life care. This study is part of a research project about nursing staff members' experiences with providing palliative care for people with severe dementia in long-term care facilities. In an earlier study, we found that structural barriers that complicated the provision of palliative care led to moral distress among nursing staff. In this study, we performed a secondary analysis of the same data set to gain a deeper understanding of nursing staff members experiences of moral distress while providing palliative care for residents with severe dementia in long-term care facilities.

Methods: A qualitative, descriptive design was used. Data were collected during in-depth interviews with 20 nursing staff members from four Norwegian long-term care facilities. Content previously identified as moral distress was reanalysed by thematic text analysis, as described by Braun and Clarke, to gain a deeper understanding of the phenomenon.
\end{abstract}

Results: The nursing staff members' experiences of moral distress were generally of two types: those in which nursing staff members felt pressured to provide futile end-of-life treatment and those in which they felt that they had been prevented from providing necessary care and treatment.

Conclusion: The findings indicate that nursing staff members' experiences of moral distress were related to institutional constraints such as time limitations and challenging prioritizations, but they were more often related to value conflicts. Nursing staff members experienced moral distress when they felt obligated to provide care and treatment to residents with severe dementia that conflicted with their own values and knowledge about good palliative care. Both education interventions focused on improving nursing staff members' skills regarding communication, ethical judgement and coping strategies; in addition, supportive and responsive leadership may have significant value with regard to reducing moral distress. Our findings indicate a need for further research on interventions that can support nursing staff members dealing with ethical conflicts in providing palliative care to residents with dementia.

Keywords: Moral distress, Ethical conflicts, Dementia, Palliative care, End-of-life care, Long-term care facilities, Qualitative methods

*Correspondence: mmi@ntnu.no

${ }^{1}$ Norwegian University of Science and Technology, Faculty of Medicine and Health Sciences, Department for Health Sciences in Aalesund, Box 1517, 6025 Aalesund, NO, Norway

Full list of author information is available at the end of the article

\section{Introduction}

This study focuses on the ethical challenges leading to moral distress experienced by nursing staff members providing palliative care to people with severe dementia in long-term care facilities. Moral distress has been widely 
explored in a variety of settings in which nurses provide acute or intensive care [1-4]. Situations that can lead to moral distress among nursing staff in long-term care facility settings have been less studied. This is particularly true in the context of the provision of palliative care to residents with severe dementia.

Dementia is a public health priority worldwide due to its rapidly increasing prevalence and poses challenges with regard to providing proper care, including end-oflife care [5-7]. Previous studies on palliative care for people with dementia have often focused on interventions to improve end-of-life practices in long-term care facilities [8-10] but have to only a small extent explored how nursing staff experience the challenges of caring for residents with severe dementia.

A literature review on the ethical issues experienced by nursing staff in long-term care facilities showed that challenges associated with communication, the lack of resources and the quality of the care provided were associated with staff burnout and moral distress [11]. In some high-income countries, approximately 50 to $80 \%$ of the residents in long-term care facilities have dementia [5, 12], and previously published studies confirm that caring for people with dementia in such facilities is related to moral distress among the nursing staff [13-16]. A prevalence study revealed that nursing staff members reported experiencing moral distress at least daily or weekly and pointed out that moral distress is a prevalent experience among staff who care for people living with dementia. The consequences of moral distress, such as frustration, physical exhaustion, a feeling of being emotionally drained and a feeling of powerlessness, were also reported as occurring at least weekly in nearly half of the participants [13]. Powerlessness was often associated with decisions made by relatives and GPs about interventions that nursing staff perceived to be futile and the cause of more suffering for the resident $[13,14$, 16]. Other studies have examined sources of moral distress in nursing staff members providing care to residents with dementia, and a lack of resources that led to a poor quality of care was reported as a main source of moral distress. Time constraints and a working culture characterized by business concerns and challenging prioritizations especially affected the weakest bedridden residents with severe dementia, and nursing staff felt guilty for spending too little time caring for each individual [14, $15,17]$. Additionally, conflicting expectations with regard to care meant that nursing staff members felt bound to provide care that conflicted with their own beliefs and knowledge, which was connected to their experience of moral distress.

Previous research shows that moral distress is prevalent among nursing staff who provide dementia care in long-term care facilities. Moral distress related to endof-life care has, however, rarely been a research topic. In light of the increasing occurrence of residents with dementia dying in long-term care facilities, there is a need for more research focusing on the challenges leading to moral distress among nursing staff members caring for residents with severe dementia in their final phase of life. In an earlier study, we found that nursing staff members experienced structural barriers that complicated the provision of palliative care to residents with severe dementia at the end of their lives in long-term care facilities and led to moral distress among nursing staff [18]. In the present study, we performed a secondary analysis of the same data set to gain a deeper understanding of nursing staff members' experience of moral distress in these situations.

\section{Moral distress}

Alongside the increasing body of research on moral distress, there has been growing interest in the way in which the concept of moral distress has been defined and understood [1, 19-22]. The concept was first defined by the philosopher Andrew Jameton in 1984: "Moral distress arises when one knows the thing to do, but institutional constraints make it nearly impossible to pursue the right course of action" [23]. He sought to capture what he observed as an emerging feature of the professional role of nursing - that nurses were unable to act in a way that was consistent with their ethical values because of institutional obstacles $[19,24]$. Later empirical research on nurses' experiences with moral distress led to the enhancement of the original definition [25-27], and in 1993, Jameton expanded his definition by distinguishing between two forms of distress, namely, initial and reactive: "Initial distress involves the feeling of frustration, anger, and anxiety people experience when faced with institutional obstacles and conflict with others about values. Reactive distress is the distress that people feel when they do not act upon their initial distress" [28].

In this new definition, he emphasized the psychoemotional responses of not acting in a morally appropriate way. Reactive distress is also referred to as "moral residue" and was later recognized as a concept that is different from, yet related to, moral distress [21, 29]. In addition to moral residue, other constructs, such as emotional distress, moral uncertainty and moral dilemmas, can all be associated with and partially overlap with moral distress. According to Jameton, the main features that distinguish moral distress from these constructs are the concurrent feeling of being constrained from taking the ethically appropriate action "when one knows the thing to". Moral judgement and institutional constraints thus appear to be necessary and sufficient conditions for 
Jameton's definition of moral distress and differentiate moral distress from other constructs, as shown in Fig. 1 $[1,19-22]$.

\section{Methods Design}

In a previous study with a qualitative and descriptive design, we interviewed 20 nursing staff members to gain insight into their experiences of providing palliative care to residents with severe dementia in long-term care facilities [18]. Although these interviews did not focus on moral distress, we found that this information was nonetheless provided. In the present study, we therefore sought answers to new research questions about moral distress to gain a deeper understanding of nursing staff members' experience of moral distress when providing palliative care for residents with severe dementia in longterm care facilities.

\section{Participants and recruitment}

The management teams of four long-term care facilities in three diverse municipalities in mid-Norway were asked to recruit nursing staff members for the study. To ensure some variation in the sample, two long-term care facilities in a mid-sized city and two in smaller municipalities were randomly selected. The manager of each unit gave the nursing staff verbal and written information about the purpose of the study. Those who wanted to participate could either contact the first author or the manager directly. No one on the research team had any relations with the participants or the units they worked at.

The size of the long-term care facilities was quite similar, with 48 to 78 beds, and they included short- and long-term units. Three of them had sheltered units for residents with a dementia diagnosis with approximately six to 12 residents. Both enrolled nurses (EN) and registered nurses $(\mathrm{RN})$ were included in the study. Although RNs bear the main responsibility for providing palliative care in long-term care facilities, ENs play an important role in direct patient care. Seven ENs and 13 RNs, five from each long-term care facility, participated in the study. The participants, all of whom were women, were employed in half-time to full-time positions. The average age was 43 years (range 28-63), and they had three to 40 years (average 18) of experience working with residents with dementia. Details of the participants are illustrated in Table 1.

\section{Data collection}

The data collection method in the study was in-depth interviews with nursing staff members working with

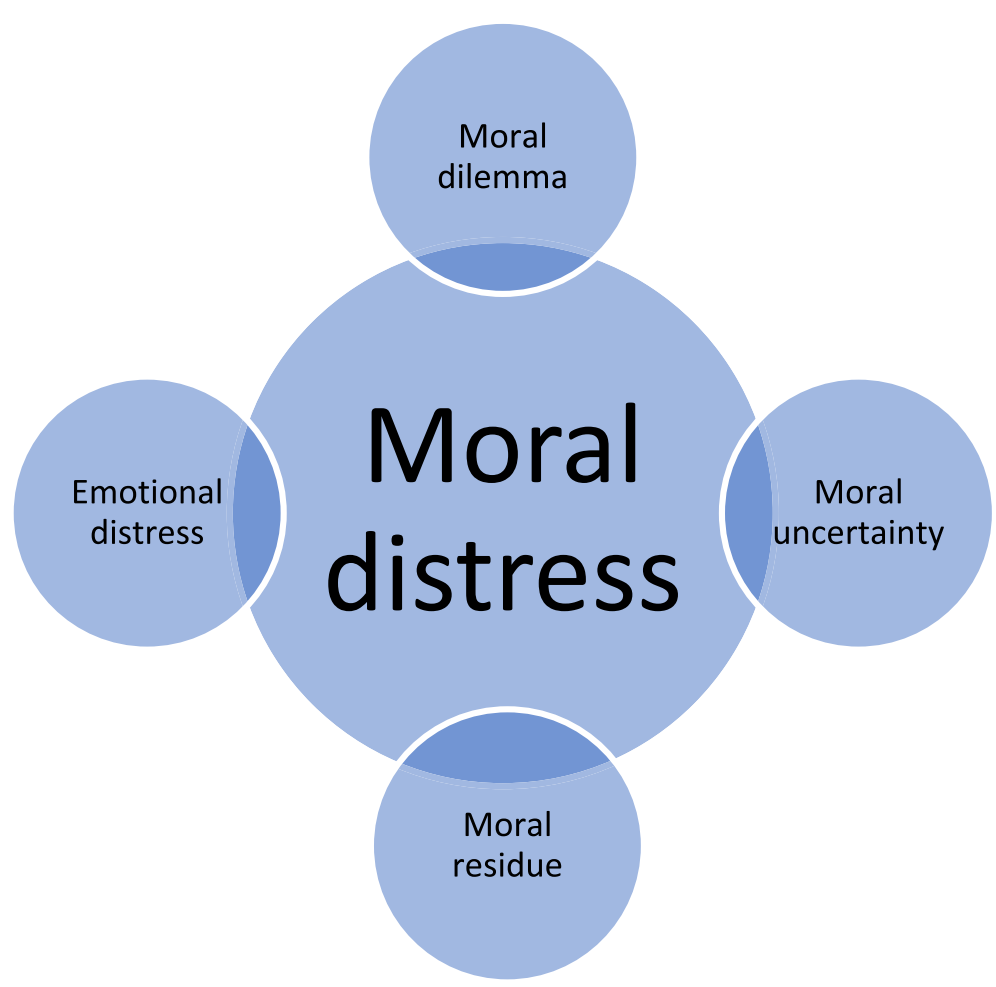

Fig. 1 Moral distress: connection with related constructs 
Table 1 Details of participants

\begin{tabular}{|c|c|c|c|c|c|c|}
\hline $\begin{array}{l}\text { Participants (all } \\
\text { women) }\end{array}$ & $\begin{array}{l}\text { Education } \\
\text { Registered nurse (RN) } \\
\text { Enrolled nurse (EN) }\end{array}$ & Unit & Age & Position & $\begin{array}{l}\text { Work experience } \\
\text { (years) }\end{array}$ & $\begin{array}{l}\text { Long-term } \\
\text { care facility } \\
\text { (LTCF) }\end{array}$ \\
\hline P1 & RN & Short-term & 34 & $100 \%$ & 10 & LTCF 1 \\
\hline P2 & $\mathrm{RN}$ & Sheltered & 50 & $75 \%$ & 25 & LTCF 1 \\
\hline P3 & EN & Sheltered & 42 & $75 \%$ & 20 & LTCF 1 \\
\hline P4 & $\mathrm{RN}$ & Long-term & 31 & $100 \%$ & 6 & LTCF 1 \\
\hline P5 & RN & Long-term & 33 & $100 \%$ & 12 & LTCF 1 \\
\hline P6 & EN & Long-term & 41 & $67 \%$ & 13 & LTCF 2 \\
\hline P7 & $\mathrm{RN}$ & Long-term & 40 & $100 \%$ & 4 & LTCF 2 \\
\hline P8 & RN & Short-term & 33 & $80 \%$ & 4 & LTCF 2 \\
\hline P9 & EN & Short-term & 63 & $50 \%$ & 40 & LTCF 2 \\
\hline P10 & $\mathrm{RN}$ & Short-term & 52 & $100 \%$ & 30 & LTCF 2 \\
\hline P11 & EN & Sheltered & 56 & $100 \%$ & 14 & LTCF 3 \\
\hline P12 & $\mathrm{RN}$ & Long-term & 28 & $80 \%$ & 5 & LTCF 3 \\
\hline P13 & RN & Sheltered & 61 & $80 \%$ & 14 & LTCF 3 \\
\hline P14 & $\mathrm{RN}$ & Long-term & 34 & $80 \%$ & 3 & LTCF 3 \\
\hline P15 & EN & Sheltered & 44 & $70 \%$ & 14 & LTCF 3 \\
\hline P16 & EN & Long-term & 51 & $80 \%$ & 29 & LTCF 4 \\
\hline P17 & RN & Sheltered & 46 & $100 \%$ & 20 & LTCF 4 \\
\hline P18 & RN & Long-term & 34 & $100 \%$ & 11 & LTCF 4 \\
\hline P19 & $\mathrm{RN}$ & Short-term & 45 & $100 \%$ & 4 & LTCF 4 \\
\hline P20 & EN & Sheltered & 53 & $88 \%$ & 30 & LTCF 4 \\
\hline
\end{tabular}

residents with dementia in long-term care facilities. The first author conducted all the in-depth interviews. She is a nurse and has experience from the field of dementia care and qualitive research. The two other authors (EG and REA) are nurses and experienced qualitative researchers.

During the interview, the first author searched for varied and rich descriptions of nursing staff members' experiences. The supportive dialogue involved asking open-ended questions, giving the informants time and space to talk without interruption, listening actively, and asking for further explanation when appropriate. A semistructured interview guide was used to help balance openness and focus during the interview [30,31]. The interviews started with the following question: What are your experiences with providing palliative care to residents with severe dementia? All the interviews were conducted in suitable meeting rooms at long-term care facilities and lasted approximately $60 \mathrm{~min}$. The interviews were recorded and transcribed verbatim by the first author.

\section{Data analysis}

The original data set was reanalysed by asking new research questions about nursing staff members' experience of moral distress when providing palliative care to residents with severe dementia in long-term care facilities. In the analyses, we used a stepwise method inspired by thematic text analysis, as described by Braun and Clarke [32]. First, the interview transcript was read several times to enable the researcher to become acquainted with the content. In the next step, all text about moral distress, as defined by Jameton $[23,28]$, was marked and separated from the rest of the material. The material about moral distress was then organized by generating and applying initial codes. This process continued until all relevant material was coded. Furthermore, themes were identified by grouping related codes. In the last step, preliminary themes were discussed and adjusted until the research group agreed on the final themes that addressed the purpose of the study. All the authors participated in the analysis. An illustration of the analysis process is presented in Table 2.

\section{Results}

The nursing staff members' experiences of moral distress could be categorized into two groups. In some cases, they felt pressured to provide futile end-of-life treatment. In other cases, they felt prevented from providing necessary care and treatment. Nursing staff members reported that many next of kin were unable to realize or accept how ill their close family members were, often demanding 


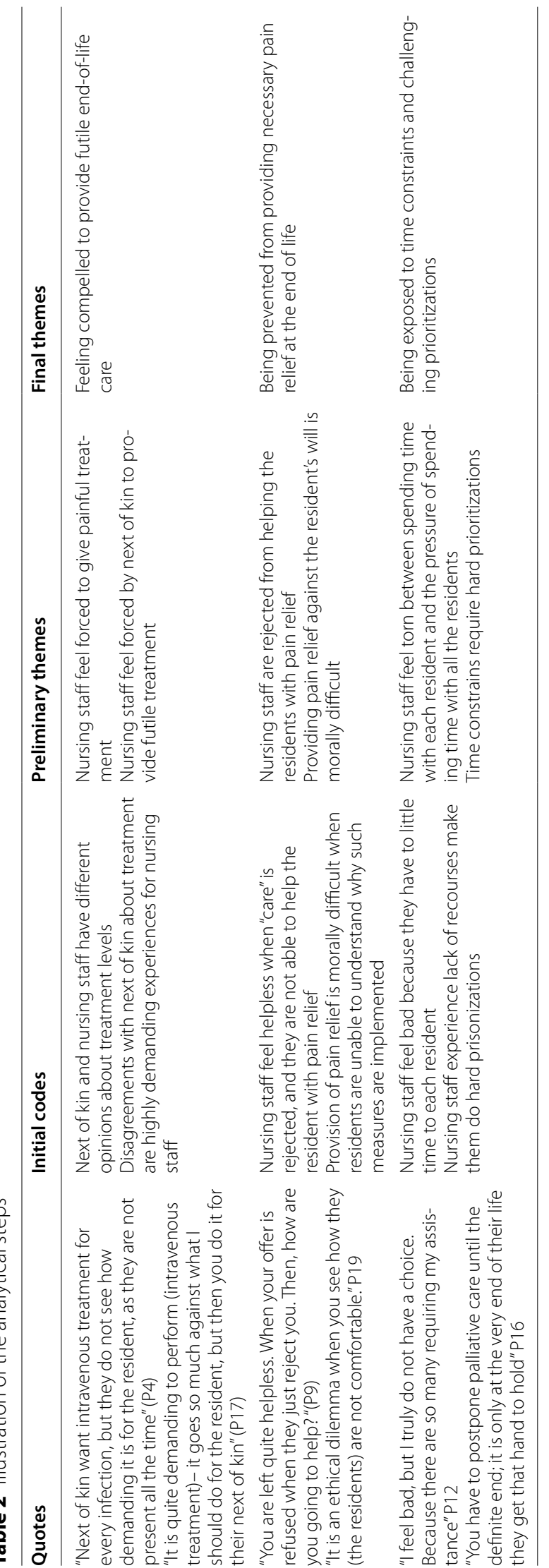


treatment that caused more suffering than relief, from the nursing staff members' point of view. Moral challenges also arose when nursing staff were obstructed from attempting to provide necessary pain relief in end-of-life care and when they were exposed to time constraints and challenging prioritizations.

\section{Feeling compelled to provide futile end-of-life care}

All participants had experienced feeling pressured to provide futile treatment to residents with severe dementia. In various ways, the participants described how some next of kin demanded that nursing staff administer treatments that the nursing staff members believed would lead to more suffering than relief. They reported that many next of kin were unable to realize or accept that their close family members were gravely ill and requested treatment that nursing staff members knew would be painful. One nurse said, "Next of kin want intravenous treatment for every infection, but they do not see how demanding it is for the resident, as they are not present all the time" (P4). The resident might appear satisfied and pain-free when next of kin were present, but the nursing staff observed increased pain, difficulties eating and other afflictions, none of which the next of kin observed during their occasional visits. Additional difficulties may arise when the next of kin resides far away, and they have not seen their family member for an extended period of time. One nurse expressed it as follows: "I have experienced them entering the patient's room, greeting their mother or father for the first time in maybe a year, and then they are shocked by what they see" (P5). These next of kin have not seen the gradual deterioration, which may have been observed by other family members, and disagreements may arise between them. These situations may be difficult for all parties, including the nursing staff, who were under the impression that the situation was clear and that there was agreement about the resident's trajectory.

Disagreements with next of kin about what is best for a resident are highly demanding experiences for nursing staff. One nurse told a story about a particularly difficult situation in which she felt forced to administer painful and useless treatment to a person with severe dementia at the end of life. The resident became increasingly ill and developed one infection after another, and the nursing staff members observed that the resident's life was ending. Nursing staff in the ward reported that the next of kin were unable to accept that their close family member was severely ill and requested continued intravenous treatment with antibiotics despite advice to the contrary from both the physician and the nurse. The nursing staff felt that the treatment imposed a greater burden on the resident rather than providing relief and that treatment continued only to appease the demands of the next of kin and not out of concern for the resident's well-being.

Such demands from next of kin were highlighted as particularly difficult when related to residents with severe dementia who were no longer able to verbally express their needs. One nurse said, "How often should you inject a person who does not understand why you are doing it, and you may have to restrain the resident a little to administer the injection in the right way. It is hard to defend when the resident expresses severe discomfort from these injections" (P4).

Multiple participants described such situations as ethical dilemmas in which they were prevented from providing good palliative care at the end of life. They experienced it as agonizing to be compelled to provide treatment that focused more on prolonging life than increasing quality of life. One nurse shared her experiences with what she called "extreme" cases related to the intravenous treatment of persons with severe dementia: "It is quite demanding to perform - it goes so much against what I should do for the resident, but then you do it for their next of kin. Because you cannot truly defend it professionally. Therefore, this is a constant dilemma" (P17).

\section{Being prevented from providing necessary pain relief at the end of life}

Being prevented from providing treatment and sufficient pain relief were moral challenges experienced by nursing staff. They reported how a lack of examination and treatment meant that some residents did not receive sufficient pain relief. One nurse shared her experiences in a difficult situation in which nursing staff had observed that a resident was in severe pain for an extended time. The nurse conferred with a physician and argued that the resident should be examined at a hospital, as the long-term care facility staff were unable to sufficiently relieve her pain. The nursing staff members expressed the despair they experienced when the resident was not scheduled for examination despite their frequent appeals to physicians. Eventually, an examination was performed, and the cause of the pain was found to be severe cancer. The nurse said that she experienced feelings of being too late with regard to providing pain relief that weighed heavily on her mind. The result was a very grim situation in which both nursing staff and next of kin knew that the resident was in severe pain until she died. The nurse related: "We did everything in our power to relieve her pain, but afterwards we all felt we had been unable to give sufficient pain relief" (P2).

Nursing staff also reported that some next of kin fear that their loved ones will receive excessive medication towards end of life and that many are particularly afraid 
of excessive morphine administration. Several participants expressed understanding the next of kin wanting what is best for their loved ones but also feeling dispirited at not being given the opportunity to provide sufficient pain relief to residents at the end of their life. To illustrate how demanding such situations can be, one nurse told a story about how painful it was to feel prevented from providing good palliative care to a resident. This nurse works in a specialized ward for persons suffering from dementia and has extensive experience as well as additional education regarding palliative care and treatment. During one evening shift, she was also responsible for a somatic longterm care ward. She was summoned because a resident suffering from dementia was terminally ill and suffering from pain. Prior to entering the patient's room, she was informed that the next of kin were very sceptical of morphine and that an agreement to not administer morphine had been made with a physician. When the nurse saw the resident, her first impulse was to administer morphine. However, because the next of kin had discussed the issue with both physicians and nursing staff assigned to the current ward, she felt compelled to abstain from administering morphine. She said, "This turned out to be an agonizing situation where I felt unable to provide sufficient care for the resident" (P13). She explained afterwards that she was left with a feeling of having been prevented from helping and providing palliative care at the end of life to the resident and a sense that the demands from the next of kin were more important than her professional assessment as a nurse.

Being prevented from providing necessary pain relief at the end of life also exacerbated nursing staff members' experiences of feeling rejected and not being given the opportunity to care for a resident in pain. Nursing staff members frequently reported finding themselves in highly demanding situations in which they were trying to provide care, but the residents responded by rejecting and challenging them. One enrolled nurse said, "You are left quite helpless. When your offer is refused, when they just reject you. Then, how are you going to help?" (P9).

The feeling of having come close to committing assault when required to use force and act in ways that the resident clearly opposes were described as painful experiences by several participants. One nurse shared her experience in a situation in which she truly felt she had failed as a nurse. An older woman with severe dementia behaved aggressively and dismissively towards the nursing staff. They observed that the woman's condition gradually worsened, and she seemed increasingly affected by pain. In the final days of her life, she suffered from multiple infections that did not respond to treatment, and she rejected all attempts at treatment and palliative care. The nurse related that the situation was very demanding. She wanted very badly to help the woman feel as comfortable as possible. When she tried to help, she was beaten and verbally assaulted. The nurse described this as imposing a major psychological strain and reported how she was unable to provide care regardless of what she did. Multiple drugs were considered, but eventually, the resident was practically sedated with morphine. The nurse said: "It was very hard. You feel inadequate and almost unable to help the resident in any other way than to sedate her with morphine" (P4).

The provision of pain relief to residents suffering from severe dementia who were unable to comprehend why such measures were being implemented was commonly experienced as a major challenge. Nursing staff explained how these situations typically arose when the residents refused to take their pills and how administering pain relief via injections felt like assault when it was performed against the resident's will. One nurse mentioned not only how she frequently resorted to using analgesic patches but also how morally difficult she found it to practically deceive the resident. She said, "It is an ethical dilemma when you see how they [the residents] are not comfortable. In addition, it is not just pain relief, it also sedation. It is hard to decide how to approach these situations because you want them to be comfortable" (P19).

\section{Being exposed to time constraints and challenging prioritizations}

Nursing staff constantly experience increased demands, as the residents admitted to long-term care facilities are severely ill and have comprehensive care needs. Resource allocation does not meet these demands. Despite this, staff are required to reduce spending. One enrolled nurse explained, "They are cutting back on everything. You must do dishes, laundry, you are doing everything. It is not just care you are required to provide... We have too few nursing staff around patients" (P16).

The participants talked about time constraints and challenging prioritizations that left bedridden residents with severe dementia particularly vulnerable. They experienced feeling torn between spending time with each resident and the pressure of spending time with all the residents. The time constraints resulted in feelings of guilt and the inability to provide the palliative care they would like to be able to give. One nurse explained that she always felt guilty because she had too little time to provide quality care. She explained this by relating an example of a situation involving a meal during which she was supposed to provide guidance to residents enabling them to feed themselves, but a lack of time led to her feeding the residents instead. She said, "I feel bad, but I truly do not have a choice. Because there are so many requiring my assistance" (P12). 
Even though the participants experienced hectic workdays characterized by time constraints and difficult prioritizations, they made the extra effort to ensure that the end of life was as pleasant as possible for residents and their next of kin. They reprioritized tasks and did their best to ensure that nursing staff were always present with dying residents. Despite nursing staff members' efforts to provide a comfortable and dignified death, the nursing staff wished they had more time to devote to each patient earlier in the course of illness. The participants reported a general lack of the resources needed to provide palliative care to residents with severe dementia. For some patients, the final phase lasts for a month, while for others, it lasts only a few days. Scarce resources mean that nursing staff have to evaluate the condition of the residents and determine if they are truly dying before they reprioritize resources or hire nursing staff to stay with the dying resident. One enrolled nurse said, "You have to postpone palliative care until the definite end; it is only at the very end of their life they get that hand to hold" (P16).

\section{Discussion}

The purpose of this study was to explore nursing staff members' experiences of moral distress when providing palliative care to residents with severe dementia in longterm care facilities at the end of life. The major findings are that nursing staff members' experiences of moral distress are related to situations in which the care and treatment provided caused the person with dementia to experience increased suffering. According to Jameton's definitions $[23,28]$, nursing staff were exposed to moral distress because they were unable to act in a way that was consistent with their ethical values and beliefs regarding good palliative care because of institutional obstacles. In his first definition (1984), moral judgement and institutional constraints seem to be necessary and sufficient conditions for moral distress, but in his later definition (1993), he includes "conflict with others about values". Institutional constraints, such as the lack of resources, that led to a poor quality of care were reported as the main source of moral distress among nursing staff caring for residents with dementia in earlier studies [14, $15,17]$. Additionally, our findings indicate that moral distress was related to institutional constraints, such as time constraints and challenging prioritizations, but that they were perhaps more often related to what Jameton described as "conflict with others about values". The most prominent cause of moral distress was the nursing staff members' experiences of feeling compelled to provide futile end-of-life treatment or feeling that they were prevented from providing necessary pain relief at the end of life. Such situations were often associated with demands from the next of kin for staff to provide care and treatment that, in their estimation, focused more on prolonging life than increasing quality of life. The line between palliative care and treatment that is considered futile may be blurred. The assessment of the appropriateness of a given treatment may depend on the staff members' knowledge of palliative care and dementia [33] and their clinical experience, and there may be differences in values among professionals and between professionals and the next of kin. Additionally, previous research identified conflicting values with regard to care as a factor contributing to moral distress among nursing staff members working with residents with dementia. Moral distress was experienced when the nursing staff members felt bound to provide care that conflicted with their own beliefs and knowledge regarding what the resident might want or need $[13,14,16]$. Conflicts between values pertaining to palliative care may be particularly difficult when the patient has severe dementia and is no longer able to verbally express themselves. Nursing staff in our study highlighted how difficult it was to feel pressured to give painful treatments to residents who expressed severe discomfort or to be prevented from helping either by the next of kin or the residents themselves.

In Jameton's 1993 definition of moral distress, he included the psycho-emotional consequences of moral distress, such as feelings of frustration, anger, and anxiety [28]. In a literature review about moral distress in nursing in the general field of care for the elderly population, the results indicate that nurses are primarily affected in two ways. Moral distress may have consequences for themselves or others and consequences for the system [34]. In our study, the nursing staff described the consequences of moral distress for themselves, such as feelings of inadequateness, frustration, and powerlessness, when they were prevented from providing what they believed to be good palliative care. Similar findings were reported in a prevalence study of moral distress in dementia care in which nearly half of the participants reported feeling frustrated, physically exhausted, emotionally drained, and powerless at least weekly as a result of moral distress [13]. Nursing staff in our study also expressed feelings of guilt and a heavy conscience, which reflect the consequences experienced by others when time constraints meant that they were unable to spend time with vulnerable bedridden residents with severe dementia and when care and treatment caused increased suffering at the end of life. Previous research highlighted the risk of becoming callous, bitter, cynical, or frustrated as a consequence of being exposed to such moral distress over time. If nursing staff members cannot or choose not to discuss or act upon the problem causing moral distress, it can contribute to issues with quality of care and patient satisfaction 
[34]. This may be in line with what Jameton describes as moral residue, which is both a contributor to and a consequence of moral distress (see Fig. 1) [21, 28, 29]. The residual effect may also create consequences for the system, such as issues of nurse retention and staff shortages [34]. Poor staffing levels, high turnover and demanding workloads are prevalent in long-term care facilities [17, $35,36]$. Hence, moral distress may have implications for recruitment to the profession [34].

How can moral distress be prevented? One strategy may be to increase nursing staff members' education regarding communication, ethical judgement and coping strategies [34, 37]. Furthermore, it is important to emphasize the value of supportive and responsive leadership with regard to confronting moral distress, as it has been shown to reduce moral distress in the context of long-term care [15].

\section{Strengths and limitations}

We consider it a strength that our study provides a real picture of the variation in Norwegian long-term care facilities. This variation is due to the inclusion of nursing staff members with different levels of education working in diverse units: sheltered units for people with dementia and short- and long-term units from four long-term care facilities. In addition, we believe that the close cooperation of the research team and its reflection on the data throughout all stages of the research process are strengths of this study.

This study has limitations, and part of the recruitment and information gathering process may have some deficiencies. The management team in each long-term care facility was asked to recruit nursing staff members who might be interested in participation in the study and give them oral and written information about the project. Regardless of this process, it seemed that some of the informants had not received sufficient information about the study and enough time to think things through and prepare for the interviews. In addition, recruitment may have been affected by the preferences of the management team. The management team members could have chosen informants that they considered suitable, and other informants who might have added important information may have been excluded. It can also be considered a weakness of the study that we did not ask questions about moral stress in the original study. Despite this, important data emerged on moral stress that can provide an important source of knowledge in the field.

\section{Conclusion}

This study found that nursing staff members experience moral distress in situations in which care and treatment cause people with severe dementia to suffer at the end of life. Moral distress was related to institutional limitations such as time constraints and challenging prioritizations but was more often related to what Jameton describes as "conflict with others about values". Moral distress was generated when the nursing staff members felt obligated to provide care and treatment to residents with severe dementia that conflicted with their own values and knowledge about good palliative care. The outcomes of moral distress may manifest internally or externally and constitute a threat to good-quality dementia care.

\section{Relevance for clinical practise}

Our findings indicate that moral distress is prevalent among nursing staff members who provide palliative care in long-term care facilities, and interventions to prevent moral distress are therefore needed. Utilizing a collaborative and palliative care approach to dementia care involving all parties in decision making could improve end-of-life care for residents and reduce the experience of moral distress among nursing staff. Additionally, education interventions focused on improving nursing staff members' skills in communication, ethical judgement and coping may be useful for preventing moral distress. Supportive and responsive leadership has also been shown to reduce moral distress.

Our findings indicate a need for further research on interventions that can support nursing staff members dealing with ethical conflicts when providing palliative care to residents with dementia. Intervention studies have been undertaken, and it is crucial to generate evidence about interventions that can prevent moral distress in dementia caregivers.

\section{Abbreviations \\ P: Participant(s); LTCF: Long-term care facility; RN: Registered nurse; EN: Enrolled nurse; GP: General practitioner.}

\section{Acknowledgements}

We would like to thank all the informants who shared their time and experiences by participating in this study.

\section{Authors' contributions}

MHM performed the data acquisition. MHM performed the majority of the analysis and interpretation, in addition to drafting the manuscript. All authors closely cooperated and were involved in reflecting on the data throughout all stages of the research process and contributed to the manuscript revisions. All authors read and approved the final manuscript.

\section{Authors' information}

MHM is an associate professor at Norwegian University of Science and Technology, Faculty of Medicine and Health Sciences, Department for Health Sciences in Aalesund, Norway. She obtained her Ph.D. in health sciences and social care from the University College of Molde and the University of Volda in 2019. She is now teaching bachelor's, master's and Ph.D. students in nursing and health sciences. Her main research interest is palliative care to people with severe dementia in long-term care. 
EG is a professor emerita at the Department of Global Public Health and Primary Care, University of Bergen, Norway. She obtained her Ph.D. in nursing sciences from the University of Bergen in 1994, and she has taught master's and Ph.D. students in health sciences. She has published several book chapters and research articles on patient experiences, health care ethics and methodology.

REA is an associate professor at Norwegian University of Science and Technology, Faculty of Medicine and Health Sciences, Department for Health Sciences in Aalesund, Norway. She obtained her Ph.D. in nursing sciences from the University of Oslo in 2014 and is now teaching bachelor's and master's and Ph.D. students in nursing and health sciences. Her main research interests are in dementia care, specifically focusing on interactions between persons with dementia and care staff, and in research collaboration between academic institutions and nursing practice.

\section{Funding}

This study received no specific grant from any funding agency in the public, commercial, or not-for-profit sectors.

\section{Availability of data and materials}

The data sets generated and/or analysed during the current study are available from the corresponding author on reasonable request.

\section{Declarations}

\section{Ethics approval and consent to participate}

This study was carried out in accordance with the guidelines of the Helsinki Declaration [38]. The regional Committee for Medical Research Ethics assessed the study and determined that the project did not fall within the committee's mandate related to the Health Research Act [39]. The study protocol was then approved by the Norwegian Science Data Services (ref. 44973). The informants gave written informed consent to participate after receiving written and verbal information about the study. Participation was voluntary, and the participants could withdraw at any time before publication without consequences.

\section{Consent for publication}

Not applicable.

\section{Competing interests}

The authors declare that they have no competing interests.

\section{Author details}

${ }^{1}$ Norwegian University of Science and Technology, Faculty of Medicine and Health Sciences," Department for Health Sciences in Aalesund, Box 1517 6025 Aalesund, NO, Norway. ${ }^{2}$ University of Bergen, Department of Global Public Health and Primary Care, Box 7804, 5020 Bergen, Norway.

\section{Received: 25 October 2021 Accepted: 25 February 2022} Published online: 03 March 2022

\section{References}

1. Morley G, Bradbury-Jones C, Ives J. What is "moral distress" in nursing? A feminist empirical bioethics study. Nurs Ethics. 2020;27(5):1297-314.

2. Altaker KW, Howie-Esquivel J, Cataldo JK. Relationships Among Palliative Care, Ethical Climate, Empowerment, and Moral Distress in Intensive Care Unit Nurses. Am J Crit Care. 2018;27(4):295-302.

3. Corley MC, Minick P, Elswick R, Jacobs M. Nurse moral distress and ethical work environment. Nurs Ethics. 2005;12(4):381-90.

4. McAndrew NS, Leske J, Schroeter K. Moral distress in critical care nursing: The state of the science. Nurs Ethics. 2018;25(5):552-70.

5. Dementia A public health priority [http://apps.who.int/iris/bitstream/ 10665/75263/1/9789241564458_eng.pdf?ua=1]

6. World Alzheimer Report 2015. The global impact of dementia. An analysis of prevalence, incidence, cost \& trends. London: Alzheimer's Disease International; 2015 [https://www.alz.co.uk/research/World AlzheimerReport2015.pdf]
7. Global action plan on the public health response to dementia 2017-2025 [https://apps.who.int/iris/bitstream/handle/10665/25961 $5 /$ ? sequence $=1]$

8. Burns M, Mcllfatrick S. Palliative care in dementia: literature review of nurses' knowledge and attitudes towards pain assessment. Int J Palliat Nurs. 2015;21(8):400-7.

9. Beck ER, Mcllfatrick S, Hasson F, Leavey G. Health care professionals' perspectives of advance care planning for people with dementia living in long-term care settings: A narrative review of the literature. Dementia. 2017;16(4):486-512.

10. Murphy E, Froggatt K, Connolly S, O'Shea E, Sampson EL, Casey D, Devane D. Palliative care interventions in advanced dementia. Cochrane Database Syst Rev. 2016;2016(12):1-37.

11. Preshaw DH, Brazil K, McLaughlin D, Frolic A. Ethical issues experienced by healthcare workers in nursing homes: Literature review. Nurs Ethics. 2016;23(5):490-506.

12. Norwegian Ministry of Health and Care Services: Dementia plan 2025 [Demensplan 2025]. In.; 2020

13. Pijl-Zieber EM, Awosoga O, Spenceley S, Hagen B, Hall B, Lapins J. Caring in the wake of the rising tide: Moral distress in residential nursing care of people living with dementia. Dementia (London, England). 2018;17(3):315-36.

14. Spenceley S, Witcher CS, Hagen B, Hall B, Kardolus-Wilson A. Sources of moral distress for nursing staff providing care to residents with dementia. Dementia (London, England). 2017;16(7):815-34.

15. Spenceley S, Caspar S, Pijl E. Mitigating Moral Distress in Dementia Care: Implications for Leaders in the Residential Care Sector. Nurs Leadersh (Tor Ont). 2017;30(4):45-59.

16. Young A, Froggatt K, Brearley SG. "Powerlessness" or "doing the right thing" - Moral distress among nursing home staff caring for residents at the end of life: An interpretive descriptive study. Palliat Med. 2017;31(9):853-60.

17. Midtbust MH, Alnes RE, Gjengedal E, Lykkeslet E. Perceived barriers and facilitators in providing palliative care for people with severe dementia: the healthcare professionals' experiences. BMC Health Serv Res. 2018;18(1):709

18. Midtbust $M H$, Alnes RE, Gjengedal E, Lykkeslet E. A painful experience of limited understanding: healthcare professionals' experiences with palliative care of people with severe dementia in Norwegian nursing homes. BMC Palliat Care. 2018;17(1):25.

19. McCarthy J, Gastmans C. Moral distress: a review of the argument-based nursing ethics literature. Nurs Ethics. 2015;22(1):131-52.

20. Morley G, Ives J, Bradbury-Jones C, Irvine F. What is "moral distress"? A narrative synthesis of the literature. Nurs Ethics. 2019;26(3):646-62.

21 Epstein EG, Delgado S. Understanding and Addressing Moral Distress. OJIN The Online Journal of Issues in Nursing. 2010;15(3):1-10.

22. Hamric AB. Empirical Research on Moral Distress: Issues, Challenges, and Opportunities. HEC Forum. 2012;24(1):39-49.

23. Jameton A. Nursing practice: The ethical issues: Englewood Cliffs. N. J: Prentice-Hall; 1984.

24. McCarthy J, Monteverde S. The Standard Account of Moral Distress and Why We Should Keep It. HEC forum : an interdisciplinary journal on hospitals' ethical and legal issues. 2018;30(4):319-28.

25 Wilkinson JM. Moral distress in nursing practice: experience and effect. Nursing forum. 1987;23:16-29.

26. Corley MC. Moral distress of critical care nurses. Am J Crit Care. $1995: 4(4): 280-5$.

27. Corley MC, Elswick RK, Gorman M, Clor T. Development and evaluation of a moral distress scale. J Adv Nurs. 2001;33(2):250-6.

28. Jameton A. Dilemmas of moral distress: moral responsibility and nursing practice. AWHONNS Clin Issues Perinat Womens Health Nurs. 1993:4(4):542-51.

29. Epstein EG, Hamric AB. Moral distress, moral residue, and the crescendo effect. J Clin Ethics. 2009;20(4):330-42.

30. Dahlberg K, Dahlberg H, Nyström M: Reflective lifeworld research, 2. edn. Lund: Studentlitteratur; 2008.

31. Kvale S, Brinkmann S: Interviews. Learning the Craft of Qualitative Research Interviewing. Los Angeles, London, New Dehli, Singapore: Sage; 2009.

32. Braun V, Clarke V. Using thematic analysis in psychology. Qual Res Psychol. 2006;3(2):77-101 
33. van der Steen JT, Radbruch L, Hertogh CM, de Boer ME, Hughes JC, Larkin P, Francke AL, Jünger S, Gove D, Firth P. White paper defining optimal palliative care in older people with dementia: a Delphi study and recommendations from the European Association for Palliative Care. Palliat Med. 2014;28(3):197-209.

34. Burston AS, Tuckett AG. Moral distress in nursing: contributing factors, outcomes and interventions. Nurs Ethics. 2013;20(3):312-24.

35. Jones L, Candy B, Davis S, Elliott M, Gola A, Harrington J, Kupeli N, Lord K, Moore K, Scott S, et al. Development of a model for integrated care at the end of life in advanced dementia: A whole systems UK-wide approach. Palliat Med. 2016;30(3):279-95.

36. Kupeli N, Leavey G, Harrington J, Lord K, King M, Nazareth I, Moore K, Sampson $\mathrm{EL}$, Jones $\mathrm{L}$. What are the barriers to care integration for those at the advanced stages of dementia living in care homes in the UK? Health care professional perspective Dementia. 2018;17(2):165-79.

37. Edwards MP, McClement SE, Read LR. Nurses'responses to initial moral distress in long-term care. J Bioethical Inquiry. 2013;10(3):325-36.

38. WMA Declaration of Helsinki - Etical Principles for Medical Research Involving Human Subjects [https://www.wma.net/policies-post/wmadeclaration-of-helsinki-ethical-principles-for-medical-research-involvinghuman-subjects/]

39. Norwegian Ministry of Health and Care Services: The Health Research Act [Lov om medisinsk og helsefaglig forskning]. In.; 2008.

\section{Publisher's Note}

Springer Nature remains neutral with regard to jurisdictional claims in published maps and institutional affiliations.

- fast, convenient online submission

- thorough peer review by experienced researchers in your field

- rapid publication on acceptance

- support for research data, including large and complex data types

- gold Open Access which fosters wider collaboration and increased citations

- maximum visibility for your research: over 100M website views per year

At BMC, research is always in progress.

Learn more biomedcentral.com/submissions 